\title{
Mouse aortic muscle cells respond to oxygen following cytochrome P450 3A13 gene transfer
}

Enrica Ciofini, Francesca Scebba, Stefano Luin, Daria Sodini, Debora Angeloni, and Flavio Coceani

\begin{abstract}
We have previously shown that a cytochrome P450 (CYP450) hemoprotein from the 3A subfamily CYP3A13 for the mouse, serves as the sensor in the contraction of the ductus arteriosus in response to increased oxygen tension. In addition, we have identified endothelin-1 (ET-1) as the effector for this response. Here, we examined whether Cyp3a13 gene transfer confers oxygen sensitivity to cultured muscle cells from mouse aorta. Coincidentally, we determined whether the same hemoprotein is normally present in the vessel. Cyp3a13-transfected aortic cells responded to oxygen, whereas no significant response was seen in native cells or in cells transfected with an empty vector. Furthermore, this oxygen effect was curtailed by the ET-1/ET $\mathrm{A}_{\mathrm{A}}$ receptor antagonist BQ-123. We also found that CYP3A13 occurs naturally in aortic tissue and its isolated muscle cells in culture. We conclude that CYP3A13 is involved in oxygen sensing, and its action in the transfected muscle cells of the aorta, as in the native cells of the ductus, takes place through a linkage to ET-1. However, the response of aortic muscle to oxygen, conceivably entailing the presence of CYP3A13 at some special site, is not seen in the native situation, and may instead unfold upon transfection of the parent gene.
\end{abstract}

Key words: aorta, ductus arteriosus, oxygen sensing, cytochrome P450, cytochrome 3A, endothelin, fetal and neonatal physiology.

Résumé : Nous avons antérieurement montré qu'une hémoprotéine cytochrome P450 (CYP450) de la sous-famille 3A, CYP3A13 chez la souris, sert de senseur dans la contraction du canal artériel en réponse à l'oxygène. Nous examinons ici si le transfert du gène Cyp3a13 confère une sensibilité à l'oxygène aux cellules musculaires en culture d'aorte de souris. Parallèlement, nous avons déterminé si la même hémoprotéine est normalement présente dans le vaisseau. Les cellules aortiques transfectées avec Cyp3a13 répondaient à l'oxygène, alors qu'aucune réponse significative n'était observée chez les cellules natives et les cellules transfectées avec un vecteur vide. De plus, cet effet de l'oxygène était réduit par l'antagoniste du récepteur ET-1/ET $\mathrm{A}_{\mathrm{A}} \mathrm{BQ}-123$. Nous avons aussi trouvé que le CYP3A13 est naturellement présent dans le tissu aortique et ses cellules musculaires en culture isolées. Nous concluons que le CYP3A13 est impliqué dans la détection d'oxygène, et son action chez les cellules musculaires aortiques transfectées tout comme chez les cellules natives du canal, s'exécute par l'intermédiaire de l'ET-1. Cependant, la réponse du muscle aortique à l'oxygène, qui implique vraisemblablement la présence de CYP3A13 dans certains sites spéciaux, n'est pas observée en situation normale et peut plutôt se manifester à la suite de la transfection d'un gène parent. [Traduit par la Rédaction]

Mots-clés : aorte, canal artériel, détection d'oxygène, cytochrome P450, cytochrome 3A, endothéline, physiologie fotale et néonatale.

\section{Introduction}

Muscle cells of the fetal ductus arteriosus contract in response to increased oxygen tension, and this feature, distinguishing the ductus from the adjoining vessels (aorta, pulmonary artery), is important for its natural closure at birth. In a previous investigation, we have identified a major oxygen sensor with a cytochrome P450 (CYP450) hemoprotein of the 3A subfamily, specifically CYP3A13, in the mouse (Baragatti et al. 2011). Coincidentally, we have strengthened a scheme for oxygen sensing wherein CYP3A13, by operating as a catalytic element in a monooxygenase reaction, generates a signal for the activation of endothelin-1 (ET-1) (Coceani and Baragatti 2012). ET-1 is, therefore, seen as the ultimate effector for the contraction, and this role is supported by work from several laboratories, including ours (Coceani et al. 1999; Takizawa et al. 2000; Taniguchi et al. 2001; Shen et al. 2002; Ågren et al. 2007). In a separate investigation, we have also pro- posed that the putative messenger linking CYP3A13 with ET-1 is the product of a joint action between arachidonic acid epoxygenase and 12(S)-lipoxygenase (Baragatti and Coceani 2011).

Our aim here was to verify the identity of the oxygen sensor by examining whether muscle cells from the mouse aorta, which are intrinsically unresponsive to oxygen but are endowed with ET-1 (Yu and Davenport 1995), acquire susceptibility to this agent upon transfection of the Cyp3a13 gene. By extension, we wished to ascertain whether any newly acquired oxygen-sensing capacity manifests itself in accordance with the scheme developed in the ductus. Added to this work was an analysis of whether CYP3A13 is constitutively expressed in the aorta and, specifically, in its muscle component.

\section{Materials and methods}

Surgical procedures and experimental protocols were approved by the Animal Care Committee of the Ministry of Health (Rome, Italy).

Received 16 October 2012. Accepted 18 December 2012.

Abbreviations: CYP450, cytochrome P450; DAPI, 4'-6-diamidino-2-phenylindole; ET-1, endothelin-1; PEI, polyethylenimine; and SNARF, 5-(and 6)-carboxy snarf-1.

E. Ciofini, ${ }^{\dagger}$ F. Scebba, ${ }^{\dagger}$ D. Sodini, and D. Angeloni. Institute of Life Sciences, Scuola Superiore Sant'Anna, 56100 Pisa, Italy.

S. Luin. ${ }^{\dagger}$ Laboratorio NEST, Scuola Normale Superiore and Istituto Nanoscienze, Consiglio Nazionale delle Ricerche, 56100 Pisa, Italy.

F. Coceani.* Institute of Life Sciences, Scuola Superiore Sant'Anna, 56100 Pisa, Italy; Istituto di Fisiologia Clinica, Consiglio Nazionale delle Ricerche, 56100 Pisa, Italy.

Corresponding author: Flavio Coceani (e-mail: coceani@sssup.it).

*Present address: Scuola Superiore Sant'Anna, Piazza Martiri della Libertà 33, 56127 Pisa, Italy.

†These authors contributed equally to this work. 
Thoracic aorta was isolated from wild-type, term fetal mice of the C57BL/6 strain (Harlan, San Pietro al Natisone, Italy), as previously reported (Costa et al. 2006; Baragatti et al. 2011). Depending on the experimental protocol, intact or endothelium-denuded vessels were used, and the procedure for endothelium removal has been described in detail elsewhere (Wang et al. 1994). In all cases, special care was taken to obtain preparations free of any adhering tissue.

Krebs-Henseleit solution for the dissections had the following composition (in mmol/L): $118 \mathrm{NaCl}, 4.7 \mathrm{KCl}, 2.5 \mathrm{CaCl}_{2}, 1 \mathrm{KH}_{2} \mathrm{PO}_{4}$, $0.9 \mathrm{MgSO}_{4}, 11.1$ dextrose, and $25 \mathrm{NaHCO}_{3}$. The solution was bubbled with $5 \% \mathrm{CO}_{2}-95 \% \mathrm{~N}_{2}(\mathrm{pH} 7.4)$ to limit any oxygen contamination from ambient air.

To assess the functional organization of any newly acquired oxygen sensor in aortic muscle cells, our original plan was to test compounds that interfere with key steps in the expected sequence being triggered by the stimulus (Coceani and Baragatti 2012). Specifically, we were going to test the suicide-substrate inhibitor of arachidonic acid epoxidation, $N$-methylsulfonyl-6-(2-)hexanamide (MS-PPOH) (Wang et al. 1998), and the ET-1/ET A $_{\mathrm{A}}$ receptor antagonist BQ-123. The former compound, however, could not be used because the ethanol necessary for solubilization, no matter how small its concentration in the final solution (i.e., 0.01\%), curtailed the oxygen response under investigation (E. Ciofini and F. Coceani, unpublished data). In this respect, aortic muscle cells in culture differed from the isolated ductus, which is not affected by the ethanol-containing vehicle (Baragatti and Coceani 2011). Conversely, BQ-123 (Calbiochem, San Diego, California, USA) presented no problem, since it was dissolved directly in a saline medium before the final solution was prepared in the recording medium (see below).

Preparation of a polyclonal rabbit antibody recognizing mouse CYP3A13 has been reported previously, and its specificity could be confirmed in the Cyp3a-l- ductus by taking advantage of the fact that CYP3A13 is the only CYP3A isoform being constitutively expressed in the vessel (Baragatti et al. 2011). The antibody itself, however, may cross-react with other members of the CYP3A subfamily and, in particular, with the CYP3A11 isoform present in the aorta (see Results). Hence, any CYP3A13 immunofluorescence being detected in the aorta may represent, in reality, a combined CYP3A13/CYP3A11 signal.

\section{Gene expression analysis}

Total RNA was obtained (see Baragatti et al. 2011) from pooled preparations of aorta ( $n=4$ pools) using TriPure isolation reagent (Roche, Indianapolis, Indiana, USA), and its yield was measured spectrophotometrically. RNA was reverse-transcribed with the QuantiTect Reverse Transcription kit (Qiagen, Milano, Italy) in accordance with the manufacturer's instructions. The cDNA product $(0.1$ or $0.2 \mu \mathrm{g} /$ pool) was used for amplification in semiquantitative and then comparative real-time PCR (qRT-PCR). qRT-PCR was employed only with CYP3A13. Primer sequences, encompassing all genes of the CYP3A subfamily, were derived from a previous study (Baragatti et al. 2011) for the semiquantitative analysis, whereas probes for qRT-PCR were obtained from an online library (Applied Biosystems, Foster City, Calif.). For semiquantitative analysis, electrophoresis of PCR products was performed on agarose gel $(1.5 \%(w / v))$ stained with ethidium bromide, and bands from aorta and reference liver or kidney tissue were visualized in parallel. qRT-PCR (40 cycles) was performed on an ABI Prism 7700 instrument using TaqMan Universal PCR mastermix (Applied Biosystems). Gene expression was quantified in triplicate by the comparative threshold cycle method (Applied Biosystems) using $\beta$-actin as the reference.

\section{Cell culture and $\mathrm{Ca}^{2+}$ imaging}

Muscle cells were isolated from endothelium-denuded aorta and were cultured as previously described (Baragatti et al. 2011), taking care to confirm their identity with an antibody against $\alpha$-actin (Sigma-Aldrich, St. Louis, Missouri, USA) and by the peculiar phenotypic appearance (Rabinovitch et al. 1989). They were then prepared for $\mathrm{Ca}^{2+}$ imaging in their native state and after being transfected with an empty vector or a vector expressing the Cyp3a13 gene. In either case, the culture lasted 3 days, with transfection being performed $24 \mathrm{~h}$ after cell isolation. For gene transfer, we used a polymer-based DNA transfection reagent (JetPEI PolyPlus Transfection kit, Euroclone, Milano, Italy) that ensured the delivery of both an empty vector (pFlag-CMV2; Sigma) and a construct (pFlag-CMV2-3A13) encoding the gene for Cyp3a13 fused at the C-terminal of the Flag tag. The fusion construct was prepared by amplifying the CYP3A13 cDNA (GenBank accession No. BC046592) inserted in pCMV-Sport6 (supplied by the I.M.A.G.E. consortium; Geneservice, Cambridge, UK), using specific $5^{\prime}$ and $3^{\prime}$ primers (forward, 5'-GAGATCTATGGACCTGATCCCAAAC-3'; and reverse, 5'-GGTACCCCTCATTCATCACCTACAGTC-3') with anchored BglII ( $5^{\prime}$ end) and KpnI ( $3^{\prime}$ end) restriction sites. The PCR products were ligated into the pGEM-T Easy vector. The amplified insert was excised following digestion with BglII and KpnI restriction enzymes and, once the BglII had been filled-in to reconstitute the frame, was ligated in the pFlag-CMV2 expression vector. Cells transfected with an empty vector served as reference.

Transfection efficiency was assessed by immunocytochemistry in a fraction of the cells. For this purpose, they were fixed first in a methanol-ethanol mixture of 1:1 $(v / v)$ and after treatment with $0.1 \%$ Triton $\mathrm{X}-100$ and $1 \% \mathrm{BSA}-0.1 \%$ Tween-20 in sequence, were incubated with mouse anti- $\alpha$ Flag antibody (dilution, 1:250; Sigma). Goat anti-mouse IgG (dilution, 1:1000; Molecular Probes, Eugene, Oregon, USA) conjugated to AlexaFluor 488 served as secondary antibody. Incubation with the nuclear marker 4'6-diamidino-2-phenylindole (DAPI; 300 mmol/L; Invitrogen, Carlsbad, Calif.) was also done before acquiring the images on a Leica DMLB fluorescence microscope. Transfection efficiency was consistently approximately $70 \%$.

Cell $\mathrm{Ca}^{2+}$ levels were measured by the fluorescence signal ratio between $\mathrm{Ca}^{2+}$-sensitive fluo-4 AM (Invitrogen) and $\mathrm{Ca}^{2+}$-insensitive 5-(and 6)-carboxy snarf-1 (SNARF; Invitrogen). SNARF was used to correct for focus shifts and mechanical artifacts that may have occurred with a prolonged recording. The subsequent procedure has been previously described in detail (Baragatti et al. 2011). Briefly, cells were placed in the loading medium $\left(15 \mathrm{~min}\right.$ at $\left.37^{\circ} \mathrm{C}\right)$ consisting of fluo- $4(10 \mu \mathrm{mol} / \mathrm{L})$ and SNARF $(9 \mu \mathrm{mol} / \mathrm{L})$ in a pluronic acid $(20 \%)$ - DMSO $(0.002 \%)$ mixture. Once loaded, they were kept in a recording medium (see Baragatti et al. 2011) for $30 \mathrm{~min}$ before being transferred to a temperature-controlled $\left(37^{\circ} \mathrm{C}\right)$ humidified chamber (PeCon, Erbach, Germany) through which a preheated 2.5\% $\mathrm{O}_{2}-5 \% \mathrm{CO}_{2}$ - balance $\mathrm{N}_{2}$ mixture was passed for baseline recording. This mixture was replaced by $30 \% \mathrm{O}_{2}-5 \% \mathrm{CO}_{2}$-balance $\mathrm{N}_{2}$ at the 40 min mark, and responses of native versus transfected (vector with or without the Cyp3a13 gene) cells were examined comparatively over a 60 min period (Protocol 1). This oxygen concentration was chosen on the basis of existing data showing, on the one hand, a steep tissue gradient for the gas (Fay 1973) with the attendant need of oxygen levels beyond the physiological range for a maximal contraction of the isolated ductus (Coceani et al. 1999) and, on the other hand, the absence of any untoward effect on the viability of the vessel and its muscle cells in culture (Rabinovitch et al. 1989; Baragatti et al. 2011). In addition, in a separate set of experiments (Protocol 2), the response of Cyp3a13transfected cells to oxygen was recorded under control conditions and during treatment with BQ-123 $(1 \mu \mathrm{mol} / \mathrm{L})$. The ET-1 antagonist was added to the medium immediately prior to introducing the cells in the recording chamber. In all cases, imaging was performed at $30 \mathrm{~s}$ intervals on an inverted confocal microscope (TCSNT, Leica) equipped with a $40 \times$ magnification oil-immersion lens. Dye excitation was provided by a $488 \mathrm{~nm}$ wavelength from an ArKr laser and was read in the fluorescein and rhodamine spectral 
bands for fluo-4 and SNARF, respectively. A total of 15-60 cells (average of 32 cells) were studied in each experiment (Protocol 1, $n=26$; and Protocol 2, $n=15$ ) using National Institutes of Health Image 1.37a software (Bethesda, Maryland, USA) for image analysis and quantification.

\section{Immunofluorescence microscopy}

Transverse sections ( $5 \mu \mathrm{m}$ thick) of frozen thoracic aorta were processed, as previously reported (Baragatti et al. 2011), to assess the subcellular localization of CYP3A13. Briefly, the hemoprotein was detected with our custom-made polyclonal rabbit antibody (dilution, 1:50), and goat anti-rabbit IgG (dilution 1:250) conjugated to FITC served as secondary antibody (Zymed, Carlsbad, Calif.). The specificity of binding was verified by omitting the primary antibody. Colocalization of immunoreactive sites with the plasma membrane and endoplasmic reticulum was ascertained with the markers wheat germ agglutinin conjugated with marine blue and BODIPY 558/568 Brefeldin A, respectively (Molecular Probes). Images were acquired on a confocal microscope (TCSSP2 on module DM IRE 2, Leica), and colocalization of signals was confirmed on three-dimensional (3-D) pictures obtained from the deconvolution of a $z$-stack of $x-y$ images (i.e., series of images along the $z$-axis) (Baragatti et al. 2011). Further elaboration with the Huygens Professional 3.2.0p7 software (Scientific Volume Imaging, Hilversum, the Netherlands) allowed calculation of the Pearson coefficient documenting the presence (values 0 to +1 ) or absence (values 0 to -1 ) of colocalization.

Localization of CYP3A13 was also assessed in cultured muscle cells, both native and transfected with/without the authentic hemoprotein (see above). For this purpose, cells were fixed in a methanol-ethanol mixture of 1:1 $(v / v)$ and after treatment with $0.1 \%$ Triton $\mathrm{X}-100$ and $1 \% \mathrm{BSA}$ in sequence, were incubated with the same primary/secondary antibody combination employed with the tissue (dilution, 1:10 and 1:500, respectively). However, in contrast to the tissue, colocalization of immunoreactive sites could only be ascertained in the endoplasmic reticulum. The plasma membrane was not included in this analysis because of an unforeseen lack of specificity of the marker wheat germ agglutinin conjugated with marine blue. In fact, despite its appropriate action in the tissue (see above), in cultured cells the marker also reacted with the nucleus. Three additional markers (compounds D-273, F34653, and D12730; Molecular Probes) proved to be equally unsuitable because of their seepage into the cytosol. Therefore, in the absence of a proper marker, the CYP3A13 hemoprotein was considered part of the plasma membrane when the immunofluorescence signal originated from within $0.5 \mu \mathrm{m}$ of the external border of cells. In all cases, images were acquired in the 3-D mode and, when feasible (i.e., with the endoplasmic reticulum), the Pearson coefficient was calculated to verify colocalization of signals.

\section{Statistical analysis}

Data are presented as the mean \pm SE. Statistical analysis used the Student's $t$ test with unpaired observations, while multiple comparisons were made with 1-way ANOVA and a mixed model ANOVA or ANCOVA followed by the Tukey's test when required (SPSS program version 19; IBM, Armonk, New York, USA; and GraphPad Prism 5.01, GraphPad Software Inc., San Diego, Calif.). Differences were considered significant at $p<0.05$.

\section{Results}

\section{Gene expression analysis}

Native aorta presented transcripts for CYP3A11 and CYP3A13, while all the remaining members of the CYP3A subfamily (i.e., CYP3A16, CYP3A25, CYP3A41, CYP3A44, CYP3A57, and CYP3A59) were absent. Figure $1 a$ shows the level of CYP3A13 expression in the vessel relative to the ductus arteriosus.
Fig. 1. Expression of CYP3A13 transcript and protein in the aorta of the term mouse fetus. (a) CYP3A13 mRNA. Relative level by quantitative RT-PCR was calculated against the ductus arteriosus (value =1). The number of tissue pools is above the column. (b) Epifluorescence image of a section incubated with CYP3A13 antibody (green, on the Web site only). Scale bar $=50 \mu \mathrm{m}$.
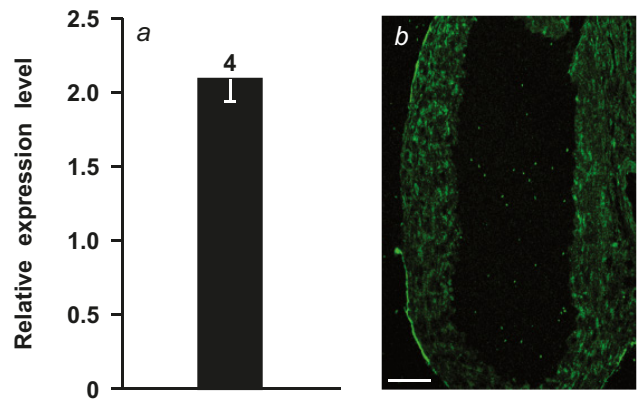

\section{Localization of CYP3A13}

Fluorescence microscopy showed a diffuse CYP3A13 immunostaining in the aorta, with no apparent difference being evident between intimal and medial layers (Fig. 1b). This staining, however, presented a spot-like appearance at higher resolution and magnification. Furthermore, through the use of appropriate markers, the staining proved to be present on the endoplasmic reticulum and, to a lesser degree, on the plasma membrane (Fig. 2). This arrangement was confirmed by deconvolution and colocalization analyses, inasmuch as they resulted in a positive Pearson coefficient for the colocalization of the CYP3A13 signal with the endoplasmic reticulum $(0.30 \pm 0.01 ; n=3)$ and with the plasma membrane $(0.15 \pm 0.02 ; n=3)$. Figure 3 indicates the actual colocalization of CYP3A13 immunostaining with the 2 structures in 3-D deconvolved images. CYP3A13 immunoreactivity was also detected in cultured muscle cells, but for technical reasons (see Materials and methods) a positive colocalization could only be demonstrated with the endoplasmic reticulum. The relative Pearson coefficient did not exhibit any obvious difference between native and transfected cells (with/without CYP3A13), and its collective value $(0.28 \pm 0.02 ; n=13)$ mimicked that of cells within the isolated tissue. Otherwise, CYP3A13 immunoreactivity was distributed diffusely across the cytoplasm, and only seldom was the signal more intense within the region of the cell being identified with the plasma membrane (see Materials and methods). This pattern did not change between the native cells and cells transfected with the hemoprotein or an empty vector $(n=97)$ (data not shown).

\section{Effect of oxygen on $\left[\mathrm{Ca}^{2+}\right]_{i}$ in aortic muscle cells}

The baseline cytosolic free $\mathrm{Ca}^{2+}$ concentration $\left[\mathrm{Ca}^{2+}\right]_{\mathrm{i}}$ was stable in muscle cells, whether native or Cyp3a13-transfected, through their exposure to $2.5 \%$ oxygen. Upon raising the oxygen concentration to $30 \%,\left[\mathrm{Ca}^{2+}\right]_{\mathrm{i}}$ of Cyp3a13-transfected cells promptly increased and the response progressed until a maximum was reached in approximately $50 \mathrm{~min}$ (Fig. 4). This progression often showed a temporary break around the 20 min mark and, consequently, acquired a biphasic profile (Fig. 4). Conversely, under the same conditions, native cells and cells transfected with an empty vector exhibited a delayed trend upwards that failed to reach significance even at the maximal time of exposure to the oxygen stimulus (Fig. 4).

\section{Effect of BQ-123 on the oxygen response in}

Cyp3a13-transfected aortic muscle cells

Pretreatment with $\mathrm{BQ}-123(1 \mu \mathrm{mol} / \mathrm{L})$ produced no obvious change in $\left[\mathrm{Ca}^{2+}\right]_{\mathrm{i}}$ of Cyp3a13-transfected muscle cells during the baseline recording at $2.5 \%$ oxygen. However, their response to $30 \%$ 
Fig. 2. Immunostaining of the mouse fetal aorta. Confocal images stained with (a) CYP3A13 antibody (green, on the Web site only), $(b$ and $c$ ) markers for endoplasmic reticulum (red, on the Web site only) and plasma membrane (blue, on the Web site only), and ( $d$ and $e$ ) CYP3A13 antibody plus superimposed markers for endoplasmic reticulum and plasma membrane, respectively; et, endothelium; smc, smooth muscle cell. Arrowheads indicate sites of colocalization. Scale bars $=10 \mu \mathrm{m}$.
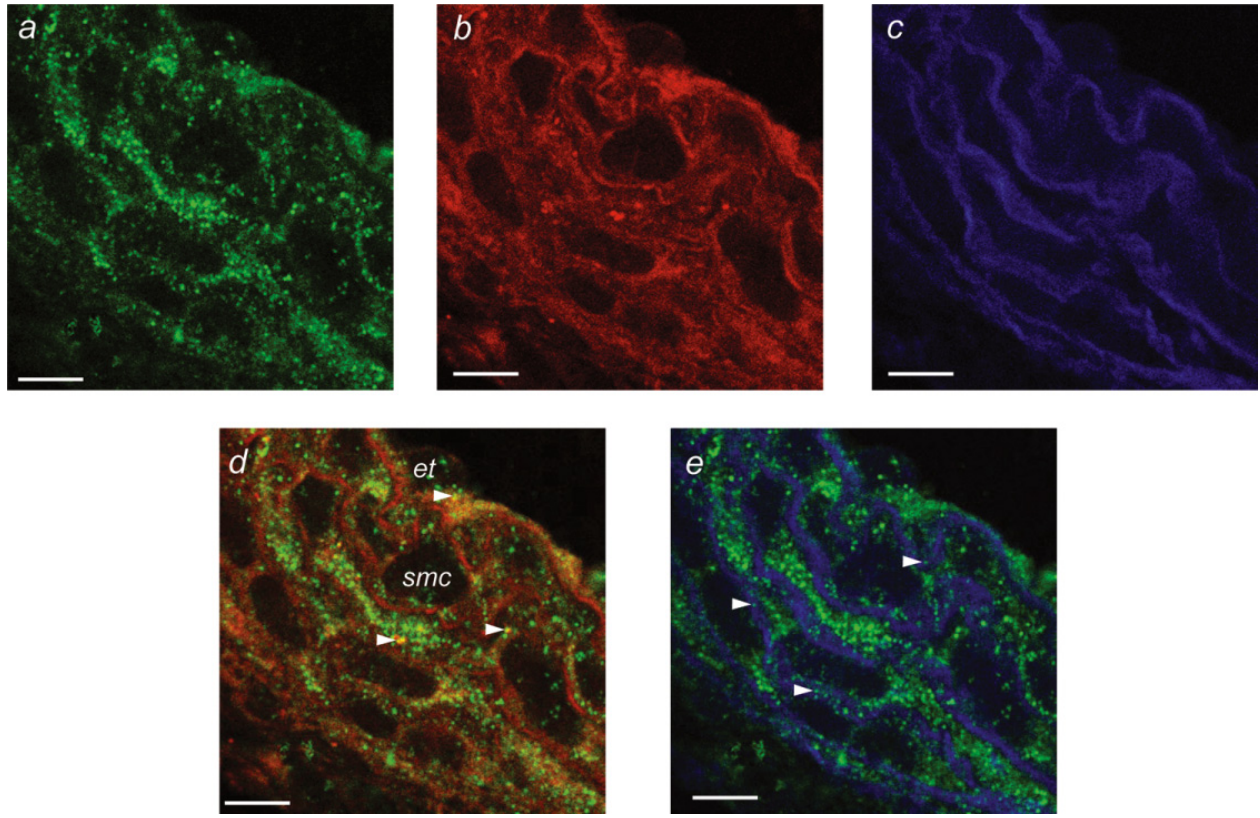

Fig. 3. Colocalization of CYP3A13 immunostaining with $(a)$ endoplasmic reticulum and $(b)$ plasma membrane markers from deconvolution of z-stacks. Arrowheads indicate some spots of high colocalization ((a) yellow or (b) magenta/white, on the Web site only). Scale bars represent $10 \mu \mathrm{m}$.

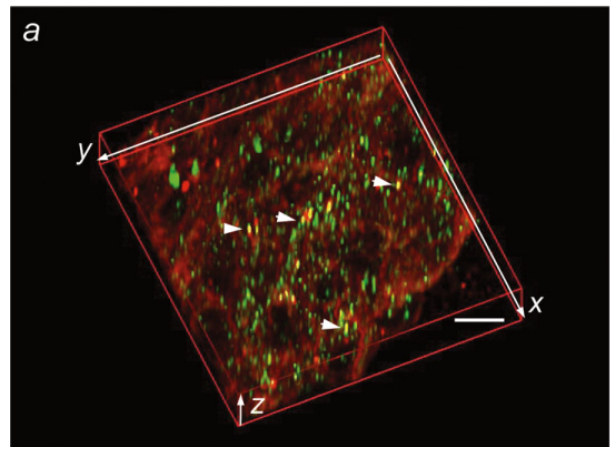

oxygen was curtailed by the inhibitor (Fig. 5). This effect showed some variability but, on the whole, was significant.

\section{Discussion}

This study shows that aortic muscle cells become responsive to oxygen upon transfection of the Cyp3a13 gene and, hence, acquire a feature that is typical of native muscle cells from the ductus. Furthermore, as in the case of the ductus (Coceani et al. 1992; Takizawa et al. 2000; Taniguchi et al. 2001; Shen et al. 2002; Ågren et al. 2007), this oxygen response is liable to inhibition by an ET-1 antagonist. Hence, one may surmise that the scheme for the oxygen-induced contraction of the ductus, implicating CYP3A13 and ET-1, respectively, as sensor and effector (Coceani and Baragatti 2012), is also applicable to the Cyp3a13-transfected aortic muscle. However, outwardly incongruent with this possibility is the observation that CYP3A13 is constitutively expressed in both vessels, indeed, with a higher expression in the aorta, notwithstanding their intrinsic difference in susceptibility to oxygen. In fact, ductus and aorta present this particular hemoprotein even in the plasma membrane of muscle cells, which is at the presumptive location for oxygen sensing in the ductus (Baragatti et al. 2011). Equally puzzling in this context is the lack of any obvious

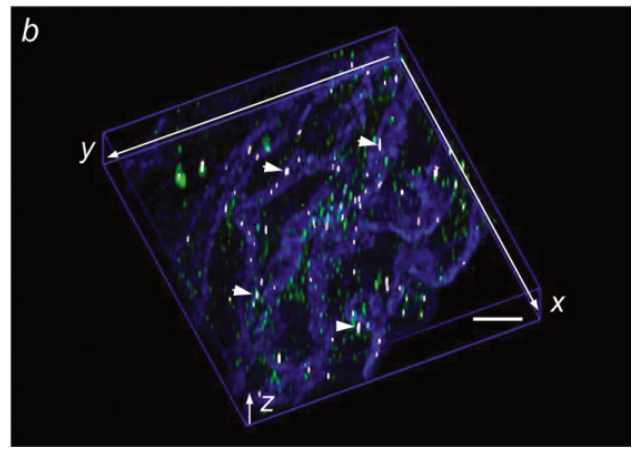

change in the CYP3A13 pattern between transfected and native muscle cells of the aorta. Our discussion will attempt to resolve these apparent inconsistencies in our proposal while elaborating on the postulated arrangement for the oxygen sensing mechanism.

Conventionally, CYP450 hemoproteins are identified with the metabolic transformation of compounds, whether endogenous or exogenous in origin, and operate at oxygen concentrations far below the expected range for any oxygen sensing mechanism (Knoblauch et al. 1981). Hence, the scheme assigning a sensing function to ductal CYP3A13 implicitly carries the notion of this hemoprotein being special on its own or through its linkage with certain components of the muscle cell. Our prior work accords with the latter alternative insofar as it envisages in the oxygen activation process taking place in the ductus a concerted operation between the sensor CYP3A13, the effector ET-1, and a hitherto unidentified product of arachidonic acid serving as their coupling agent (Coceani and Baragatti 2012). With this arrangement, it follows that CYP3A13 may not be able to ensure a response to oxygen without its connected elements. Any such lack of coordination among individual components of the oxygen sensing complex could well explain the divergent behaviour of aorta compared with the ductus in their native state. This reasoning, however, 
Fig. 4. Effect of oxygen on cytosolic $\mathrm{Ca}^{2+}$ in aortic smooth muscle cells. Native cells (open circle; $n=10$ ), cells transfected with empty vector (half-solid circle; $n=7$ ), and cells transfected with Cyp3a13 (solid circle; $n=9$ ). Cells were loaded with fluo-4 and SNARF (see Materials and methods), and recordings were made for $20 \mathrm{~min}$ at $2.5 \%$ oxygen before the switch (time 0 ) to $30 \%$ oxygen. Results are presented as the ratio of fluo-4 to SNARF divided by the baseline value at time $0\left(\Delta_{\mathrm{f} / \mathrm{f}}\right)$. Mixed model ANCOVA showed a significant effect of treatment $(p<0.001)$, while effects of time and the interaction between time and treatment were not significant. The curve for Cyp3a13-transfected cells differed significantly from the curves for cells transfected with an empty vector $(p=0.017)$ and native cells $(p<0.001)$, while no difference was noted between the latter 2 curves $(p=0.358)$ (ANCOVA followed by Tukey's test). Oneway ANOVA evidenced a significant temporal trend for curves relative to cells transfected with Cyp3a13 $(p<0.001)$ and an empty vector $(p=0.022)$, but significance by the subsequent Tukey's test was obtained only with the former $(p<0.01$ at asterisks). The same ANOVA on the curve for native cells gave a $p$-value of 0.311 . Note that the Tukey's test for the curve deriving from cells transfected with an empty vector gave a $p$-value of 0.054 at the 60 min mark compared with the baseline, with the power for this comparison being 0.223 (i.e., 17 replicates for 0.8 ). In this and the following figure, baseline recordings at $2.5 \%$ oxygen were consistently stable (not shown).

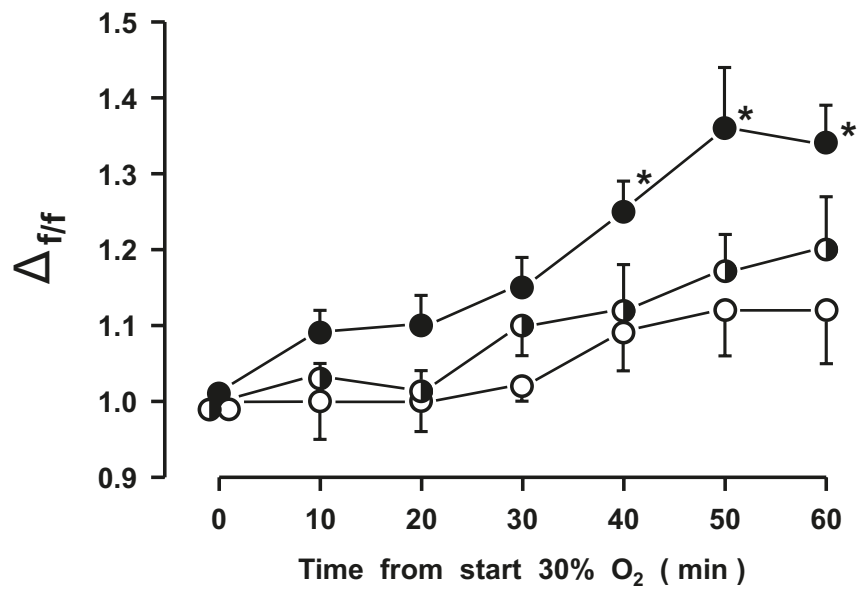

hardly reconciles with the notion that the same hemoprotein is constitutively expressed in aortic muscle. Unless, of course, one makes a further assumption and surmises that the transfection process, with its attendant perturbation of the cellular milieu, allows the insertion of newly formed CYP3A13 into a critical place and (or) operational complex for oxygen sensing. Consistent with this concept is the facile aggregation of CYP450 hemoproteins into dynamic complexes that may be modified on functional demands (Bassard et al. 2012). The turnover time of the CYP3A hemoprotein (Eliasson et al. 1994) would make any such event feasible within the interval between gene transfer and exposure to oxygen. Clearly, the idea of a dichotomy in the modality of CYP3A13 expression, separating native from transfected cells, is speculative and would entail further investigation. Here, it suffices to say that oxygen sensing, figuring prominently in ductal muscle, may be reproduced elsewhere with an appropriate intervention. This possibility not only is conceptually important, but may also open the way to better means for the study of the sensor itself.

A final point, deserving a comment, concerns the actual detection of CYP3A13 in cultured muscle cells of the aorta. It has previously been reported that CYP450 expression rapidly abates in culture (Loot et al. 2008), hence making this particular preparation unsuited in principle for a study of hemoproteins. However,
Fig. 5. Effect of BQ-123 $(1 \mu \mathrm{mol} / \mathrm{L})$ on the response of Cyp3a13transfected aortic muscle cells to $30 \%$ oxygen. Solid and open circles refer to untreated and treated cells ( $n=7$ and 8 ), respectively. Two-way mixed model ANOVA showed a significant effect of both treatment $(p=0.023)$ and time $(p<0.001)$, while the interaction between treatment and time was not significant. ${ }^{*}, p<0.01$ compared with the baseline (ANOVA followed by Tukey's post-hoc test).

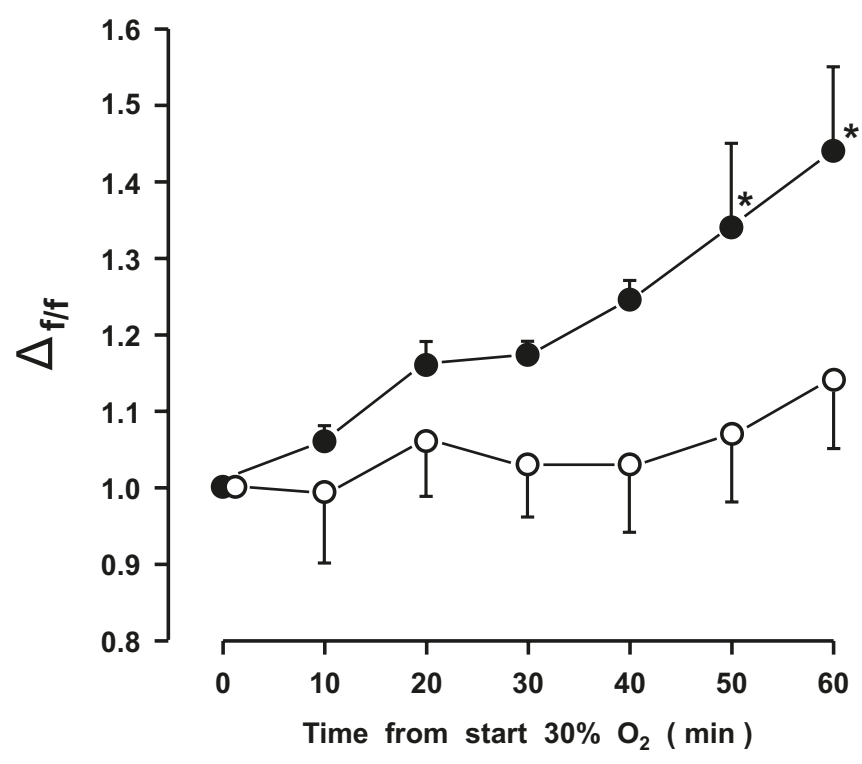

we did not experience any such difficulty, suggesting the occurrence of some exceptional feature in either the vessel or the CYP3A13 hemoprotein itself.

In conclusion, our study shows that Cyp3a13 gene transfer makes a vascular muscle cell that is intrinsically unresponsive to the agent become oxygen-sensitive. Hence, transfected cells mimic native muscle cells from the ductus in this respect. Still undefined is the actual arrangement of the sensing CYP3A13 in aortic muscle cells, with a potential difference emerging between native and post-transfection conditions.

\section{Acknowledgements}

This work was supported by the Italian Ministry of Education and Research Grant PRIN 2007E7Y7R (to F.C.). D.S. is the recipient of a postdoctoral fellowship of the Scuola Superiore Sant'Anna. The assistance of A. Ripoli with the statistical analysis is gratefully acknowledged.

\section{References}

Baragatti, B., and Coceani, F. 2011. Arachidonic acid epoxygenase and 12(S)-lipoxygenase: evidence of their concerted involvement in ductus arteriosus constriction to oxygen. Can. J. Physiol. Pharmacol. 89(5): 329-334. doi: 10.1139/y11-025. PMID:21619415.

Baragatti, B., Ciofini, E., Scebba, F., Angeloni, D., Sodini, D., Luin, S., et al. 2011. Cytochrome P-450 3A13 and endothelin jointly mediate ductus arteriosus constriction to oxygen in mice. Am. J. Physiol. Heart Circ. Physiol. 300(3): H892-H901. doi:10.1152/ajpheart.00907.2010. PMID:21193583.

Bassard, J.-E., Mutterer, J., Duval, F., and Weick-Reichhart, D. 2012. A novel method for monitoring the localization of cytochromes P450 and other endoplasmic reticulum membrane associated proteins: a tool for investigating the formation of metabolons. FEBS J. 279: 1576-1583. doi:10.1111/j.1742-4658. 2011.08312.x. PMID:21851555.

Coceani, F., and Baragatti, B. 2012. Mechanisms of ductus arteriosus closure. Semin. Perinatol. 36: 92-97. doi:10.1053/j.semperi.2011.09.018. PMID: 22414879.

Coceani, F., Kelsey, L., and Seidlitz, E. 1992. Evidence for an effector role of endothelin in closure of the ductus arteriosus at birth. Can. J. Physiol. Pharmacol 70(7): 1061-1064. doi:10.1139/y92-146. PMID:1451028.

Coceani, F., Liu, Y.-A., Seidlitz, E., Kelsey, L., Kuwaki, T., Ackerley, C., et al. 1999. Endothelin A receptor is necessary for $\mathrm{O}_{2}$ constriction but not closure of ductus arteriosus. Am. J. Physiol. Heart Circ. Physiol. 277(4): H1521-H1531.

Costa, M., Barogi, S., Socci, N.D., Angeloni, D., Maffei, M., Baragatti, B., et al. 
2006. Gene expression in ductus arteriosus and aorta: comparison of birth and oxygen effects. Physiol. Genomics. 25(2): 250-262.

Eliasson, E., Mkrtchian, S., Halpert, J.R., and Ingelman-Sundberg, M. 1994 Substrate-regulated, cAMP-dependent phosphorylation, denaturation, and degradation of glucocorticoid-inducible rat liver cytochrome P450 3A1. J. Biol. Chem. 269(28): 18378-18383.

Fay, F.S. 1973. Biochemical basis for response of ductus arteriosus to oxygen. In Fetal and Neonatal Physiology. Edited by K.S. Comline, K.W. Cross, G.S. Dawes, and P.W. Nathanielsz. Cambridge University Press, New York, N.Y. pp. 136-140.

Knoblauch, A., Sybert, A., Brennan, N.J., Sylvester, J.T., and Gurtner, G.H. 1981. Effect of hypoxia and CO on a cytochrome-mediated reaction in rabbit lungs. J. Appl. Physiol. 51(6): 1635-1642. PMID:7319893.

Loot, A.E., Popp, R., Fisslthaler, B., Vriens, J., Nilius, B., and Fleming, I. 2008. Role of cytochrome P450-dependent transient receptor potential V4 activation in flow-induced vasodilatation. Cardiovasc. Res. 80(3): 445-452. doi:10.1093/cvr/ cvn207. PMID:18682435.

Rabinovitch, M., Boudreau, N., Vella, G., Coceani, F., and Olley, P.M. 1989. Oxygen-related prostaglandin synthesis in ductus arteriosus and other vascular cells. Pediatr. Res 26(4): 330-335. doi:10.1203/00006450-19891000000009. PMID:2508051.

Shen, J., Nakanishi, T., Gu, H., Miyagawa-Tomita, S., Wu, G.-R., Momma, K., et al. 2002. The role of endothelin in oxygen-induced contraction of the ductus arteriosus in rabbit and rat fetuses. Heart Vessels, 16(5): 181-188. doi:10.1007| s003800200019. PMID:12181591.

Takizawa, T., Horikoshi, E., Shen, M.-H., Masaoka, T., Takagi, H., Yamamoto, M., et al. 2000. Effects of TAK-044, a nonselective endothelin receptor antagonist, on the spontaneous and indomethacin- or methylene blue-induced constriction of the ductus arteriosus in rats. J. Vet. Med. Sci. 62(5): 505-509. doi:10. 1292/jvms.62.505. PMID:10852399.

Taniguchi, T., Azuma, H., Okada, Y., Naiki, H., Hollenberg, M.D., and Muramatsu, I. 2001. Endothelin-1-endothelin receptor type A mediates closure of rat ductus arteriosus at birth. J. Physiol. 537(2): 579-585. doi:10.1111/ j.1469-7793.2001.00579.x. PMID:11731587.

Wang, M.-H., Brand-Schieber, E., Zand, B.A., Nguyen, X., Falck, J.R., Balu, N., et al. 1998. Cytochrome P450-derived arachidonic acid metabolism in the rat kidney: characterization of selective inhibitors. J. Pharmacol. Exp. Ther. 284(3): 966-973. PMID:9495856.

Wang, Y., Mercer-Connolly, A., Lines, L., Toyoda, O., and Coceani, F. 1994. Endothelium-denuded pulmonary resistance arteries from the fetal lamb: preparation and response to vasoactive agents. J. Pharmacol. Toxicol. Methods, 32(2): 85-91. doi:10.1016/1056-8719(94)90058-2. PMID:7865866.

Yu, J.C.M., and Davenport, A.P. 1995. Secretion of endothelin-1 and endothelin-3 by human cultured vascular smooth muscle cells. Br. J. Pharmacol. 114(2): 551-557. doi:10.1111/j.1476-5381.1995.tb13262.x. PMID:7881755.

Ågren, P., Cogolludo, A.L., Kessels, C.G.A., Pérez-Vizcáino, F., De Mey, J.G.R., Blanco, C.E., et al. 2007. Ontogeny of chicken ductus arteriosus response to oxygen and vasoconstrictors. Am. J. Physiol. Regul. Integr. Comp. Physiol 292(1): R485-R495. doi:10.1152/ajpregu.00204.2006. PMID:16917023. 